\title{
Inactivation of Severe Acute Respiratory Coronavirus Virus 2 (SARS-CoV-2) and Diverse RNA and DNA Viruses on Three-Dimensionally Printed Surgical Mask Materials
}

\author{
Jennifer L. Welch PhD 1,2,3,a, Jinhua Xiang MD ${ }^{1,2,3, a}$, Samantha R. Mackin BS ${ }^{3}$, Stanley Perlman MD, PhD ${ }^{3}$, Peter Thorne PhD, \\ Patrick O’Shaughnessy $\mathrm{PhD}^{4}$, Brian Strzelecki BS ${ }^{5}$, Patrick Aubin $\mathrm{PhD}^{6,7}$, Monica Ortiz-Hernandez $\mathrm{MS}^{6,7}$ and \\ Jack T. Stapleton MD ${ }^{1,2,3}$ (D) \\ ${ }^{1}$ Medical Service, lowa City Veterans' Affairs Medical Center, lowa City, lowa, ${ }^{2}$ Department of Internal Medicine, Carver College of Medicine University of lowa, \\ lowa City, lowa, ${ }^{3}$ Department of Microbiology and Immunology, Carver College of Medicine, University of Iowa, lowa City, lowa, ${ }^{4}$ Department of Occupational \\ and Environmental Health, College of Public Health, University of Iowa, lowa City, lowa, ${ }^{5}$ A Puget Sound Health Care System, Seattle, Washington, ${ }^{6}$ Center for \\ Limb Loss and MoBility (CLiMB), VA Puget Sound Health Care System, Seattle, Washington and ${ }^{7}$ Department of Mechanical Engineering, University of \\ Washington, Seattle, Washington
}

\section{Abstract}

Background: Personal protective equipment (PPE) is a critical need during the coronavirus disease 2019 (COVID-19) pandemic. Alternative sources of surgical masks, including 3-dimensionally (3D) printed approaches that may be reused, are urgently needed to prevent PPE shortages. Few data exist identifying decontamination strategies to inactivate viral pathogens and retain 3D-printing material integrity.

Objective: To test viral disinfection methods on 3D-printing materials.

Methods: The viricidal activity of common disinfectants (10\% bleach, quaternary ammonium sanitizer, $3 \%$ hydrogen peroxide, or $70 \%$ isopropanol and exposure to heat $\left(50^{\circ} \mathrm{C}\right.$, and $\left.70^{\circ} \mathrm{C}\right)$ were tested on four $3 \mathrm{D}$-printed materials used in the healthcare setting, including a surgical mask design developed by the Veterans' Health Administration. Inactivation was assessed for several clinically relevant RNA and DNA pathogenic viruses, including severe acute respiratory coronavirus virus 2 (SARS-CoV-2) and human immunodeficiency virus 1 (HIV-1).

Results: SARS-CoV-2 and all viruses tested were completely inactivated by a single application of bleach, ammonium quaternary compounds, or hydrogen peroxide. Similarly, exposure to dry heat $\left(70^{\circ} \mathrm{C}\right)$ for 30 minutes completely inactivated all viruses tested. In contrast, $70 \%$ isopropanol reduced viral titers significantly less well following a single application. Inactivation did not interfere with material integrity of the $3 \mathrm{D}$-printed materials.

Conclusions: Several standard decontamination approaches effectively disinfected 3D-printed materials. These approaches were effective in the inactivation SARS-CoV-2, its surrogates, and other clinically relevant viral pathogens. The decontamination of 3D-printed surgical mask materials may be useful during crisis situations in which surgical mask supplies are limited.

(Received 6 July 2020; accepted 8 August 2020; electronically published 12 August 2020)

Severe acute respiratory syndrome coronavirus 2 (SARS CoV-2) recently emerged as a highly transmissible human pathogen that rapidly escalated into a global pandemic. ${ }^{1}$ SARS CoV-2 is the causative agent of coronavirus disease 2019 (COVID-19), causing significant respiratory distress and mortality accounting for $>18.1$ million confirmed cases and $\sim 691,000$ deaths worldwide as of August 4,2020. ${ }^{2}$ Six pathogenic coronaviruses are known to infect humans. Of these, SARS CoV-1, Middle East respiratory syndrome coronavirus (MERS-CoV), and now SARS CoV-2 are

Author for correspondence: Jack T. Stapleton, E-mail: jack-stapleton@uiowa.edu

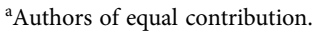

Cite this article: Welch JL, et al. (2021). Inactivation of Severe Acute Respiratory Coronavirus Virus 2 (SARS-CoV-2) and Diverse RNA and DNA Viruses on ThreeDimensionally Printed Surgical Mask Materials. Infection Control \& Hospital Epidemiology, 42: 253-260, https://doi.org/10.1017/ice.2020.417 considered highly pathogenic. ${ }^{3,4}$ Human-to-human transmission of SARS CoV-2 occurs at an elevated rate compared to SARS $\mathrm{CoV}$, which shares considerable sequence homology $(79 \%)^{4-6}$

Until there is an effective vaccine and/or therapeutic approach to treat COVID-19, SARS-CoV-2 control strategies are focused on transmission prevention, including social distancing, hand washing, and use of personal protective equipment (PPE). ${ }^{7}$ The increased demand for and shortages of PPE in healthcare and other essential workplace settings has created a need to address decontamination strategies and reuse of PPE. The Veterans' Health Administration (VHA) recently began developing a supplemental surgical mask. ${ }^{8}$ The use of 3-dimensional (3D) printing technology within the healthcare industry is not new; it is currently used in applications such as drug delivery systems, ${ }^{9,10}$ surgery, ${ }^{11,12}$ personalized medicine, ${ }^{13-15}$ and biomedical engineering. ${ }^{16,17}$ 
In response to current needs during the COVID-19 pandemic, 3D printed technology has expanded to include the production of ventilators and other respiratory support equipment, ${ }^{18,19}$ nasopharyngeal swabs, ${ }^{20}$ face shields, ${ }^{21}$ and face masks. ${ }^{22,23}$

In 2006, the US Department of Health and Human Services (DHHS) asked the Institute of Medicine (IOM) to convene a committee to conduct an evaluation of measures that would permit the reuse of disposable N95 respirators and reusable face masks in healthcare settings. The IOM committee followed criteria to prevent transmission of the 2003 SARS-CoV. The IOM committee found no validated method of decontamination that met criteria for decontamination of N95 respirators or surgical masks. ${ }^{24}$

Although reuse of PPE masks was considered before the SARSCoV-2 pandemic, literature on potential decontamination strategies are limited and guidelines are often institution- or manufacturer specific. ${ }^{25,26}$ In this study, we assessed the ability of materials used in the $3 \mathrm{D}$ printing of surgical masks to be decontaminated for human viral pathogens including SARS-CoV-2 using common disinfection methods. Data showing that human coronaviruses may survive on various surfaces for up to 9 days makes identification of decontamination strategies against pathogenic viruses increasing important not only during the SARS-CoV-2 pandemic but also for future viral transmission prevention practices. ${ }^{27}$ Our goal was to identify practical decontamination procedures that are easily adapted across healthcare and other workplace settings. We assessed the VHA 3D-printed mask material and 3 additional $3 \mathrm{D}$-printing materials for virus inactivation in these studies.

\section{Materials and methods}

Healthy volunteers were invited to participate in the study. Following written informed consent, anticoagulated blood was obtained using heparin collection tubes. This study was approved by the University of Iowa Institutional Review Board.

We used numerous viruses in these studies. Enterovirus 68 (EV68), vaccinia virus, influenza A H1N1 and human coronavirus (HCoV-229E) were all supplied by the American Type Culture Collection (ATCC). We also tested yellow fever virus (YFV, provided by Sanofi), HIV-1 (provided by the NIH AIDS Reagent Program), mumps virus (provided by Merck), adenovirus (provided by University of Iowa Viral Vector Core), Zika virus (kindly provided by DrWendy Maury, University of Iowa), SARS CoV-2 (Seattle Washington strain MN985325), murine hepatitis virus (MHV A59 strain, kindly provided by Dr Stanley Perlman, University of Iowa), and Dengue viruses types 1-4 (DENV, kindly provided by Sarah George, St Louis University). Virus titers were determined in appropriate cell lines by median tissue culture infectious dose $\left(\mathrm{TCID}_{50}\right)$ or p24 enzyme-linked immunosorbent assay (ELISA) for HIV-1. ${ }^{28,29}$ All SARS-CoV-2 work was performed at the University of Iowa Biosafety Level (BSL) 3 core facility, and all other virus studies were conducted at the Iowa City Veterans' Affairs Infectious Diseases Research Laboratory under BSL2 conditions.

Vero and MDCK cells were purchased from the ATCC, and HEK293 and MT-2 cells were obtained from the NIH AIDS Reagent Program. MRC-5 was purchased from Sigma-Aldrich (St Louis, MO), and VeroE6 and $17 \mathrm{Cl}-1$ were provided by Dr Stanley Perlman. Cells were maintained in media as previously described. ${ }^{28,30-32}$

The VHA supplemental surgical face mask $^{8}$ being developed is $3 \mathrm{D}$ printed using Multi-Jet Fusion (MJF) technology and a powder-based polyamide-12 (PA12) material (HP 3D HR CB
PA 12 - Hewlett-Packard, Palo Alto, CA). The surgical face mask incorporates a removable filter (not tested in this study). The 3D-material is a biocompatible thermoplastic used in medical applications ${ }^{33}$ and is believed to be resistant to disinfectants. Thus, it may be reused many times following standard approaches to disinfection. The surgical face mask design has undergone review in a clinical setting and was found appropriate when fabricated with the printer type and materials specified. ${ }^{23}$

Virus titers were determined by determining the $\mathrm{TCID}_{50}$ in the cognate cell line as previously described ${ }^{28,34,35}$ or by p24 ELISA (R\&D Systems) for HIV-1. ${ }^{29}$

\section{Inactivation studies}

Disks were printed in Seattle and shipped to Iowa for testing. Each virus $(100 \mu \mathrm{L})$ was added to $2 \mathrm{~cm}$ diameter $\times 1.5$-mm-thick 3 -D printed circular disks (PA12 material unless otherwise noted). Disks were allowed to dry in a laminar flow safety cabinet at room temperature for 2 hours. Disks were inactivated either by thermal or chemical treatment (as described in the Results section). Viruses were recovered by placing the disks into a 12 -well culture plate, adding $200 \mu \mathrm{L}$ media to each well, pipetting 6 times, then removing the media and storing at $-80^{\circ} \mathrm{C}$ until determining the viral titer (within 1 week in all cases). Virus infectivity following each inactivation method was compared to control disks treated only with phosphate-buffered saline (PBS), and the reduction in infectivity ( $\log _{10}$ or $\mathrm{p} 24$ ) was calculated. Control and postinactivation virus titers were performed in a minimum of 3 biological replicate experiments.

\section{Statistical analysis}

Statistical analyses were performed using GraphPad software V8.2 (GraphPad Prism). We used 2-tailed Student $t$ tests to compare results between treatment and control virus titers from triplicate experiments. $P<.05$ was considered statistically significant.

\section{Results}

To determine the effectiveness of inactivation of viruses applied to $3 \mathrm{D}$ printing material, we examined a diverse group of human viral pathogens that have different virion structures (envelope vs nonenveloped), different genome compositions (DNA vs RNA), and genome structures (single strand vs double strand) ${ }^{36}$ In light of the COVID-19 epidemic, we included 1 human low pathogenicity coronavirus (229E), 1 nonhuman coronavirus (MHV), and SARS-CoV-2 in most inactivation experiments. We also included a variety of healthcare-relevant human pathogens (Table 1).

\section{Chemical inactivation}

Chemical inactivation studies were performed by treating the virus-coated disks with a single application (by wipe) of bleach (10\%; $0.6 \%$ hypochlorite), isopropyl alcohol (70\% IPA), a commercial quaternary ammonium compound (Sani-Cloth germicidal disposable wipe AF3; n-Alkyl [ $68 \% \mathrm{C}_{12}, 32 \% \mathrm{C}_{14}$ ] dimethyl ethylbenzyl ammonium chlorides - 0.14\%; n-Alkyl [60\% $\mathrm{C}_{14}, 30 \% \mathrm{C}_{12}, 5 \% \mathrm{C}_{18}$ ] dimethyl benzyl ammonium chlorides $-0.14 \%$ ), control wipe (PBS), or a no-wipe control as indicated. After a single application, disks were allowed to dry ( $<5$ minutes in all cases) and virus recovery was measured.

Nearly complete recovery of virus from 3D-printed surgical mask materials was observed, and wiping the disk with PBS did not significantly reduce virus titers compared to the no-wipe 
Table 1. Viruses Used in Inactivation Studies

\begin{tabular}{|c|c|c|c|c|c|}
\hline Virus & Strain & Genome & Envelope & Size $(n m)$ & Cell Type \\
\hline SARS CoV-2 & Seattle & RNA SS + & Y & $65-125$ & VeroE6 \\
\hline $\mathrm{HCOV}$ & $229 \mathrm{E}$ & RNA SS + & Y & $80-150$ & MRC-5 \\
\hline MHV & A59 & RNA SS + & Y & $80-160$ & $17 \mathrm{Cl}-1$ \\
\hline Mumps & Jeryl Lynn strain & RNA SS - & Y & $100-600$ & Vero \\
\hline YFV & 17D strain & RNA SS + & $Y$ & $25-65$ & Vero \\
\hline Vaccinia & Walter Reed & DNA DS & Y & $200-300$ & Vero \\
\hline Adenovirus & Type 5 & DNA DS & $\mathrm{N}$ & $70-100$ & HEK293 \\
\hline EV68 & US/IL/14-18952 & RNA SS + & $\mathrm{N}$ & $25-30$ & MRC-5 \\
\hline Zika & PR & RNA SS + & Y & $40-50$ & Vero \\
\hline Dengue & Serotypes 1-4 & RNA SS + & $Y$ & $40-60$ & Vero \\
\hline Influenza A H1N1 & A/Virginia/ATCC2/2009 & RNA SS - & Y & $80-120$ & MDCK \\
\hline HIV-1 & NL4-3 gp41 (36G) N42S & RNA SS + & Y & $110-145$ & MT-2 \\
\hline
\end{tabular}

Note. SS, single strand; DS, double strand; +, positive polarity; -, negative polarity; Y, enveloped virus; N, nonenveloped virus; HCoV human coronavirus; MHV, mouse hepatitis virus; $\mathrm{YFV}$, yellow fever virus; EV68, enterovirus 68; HIV-1, human immunodeficiency virus type 1.
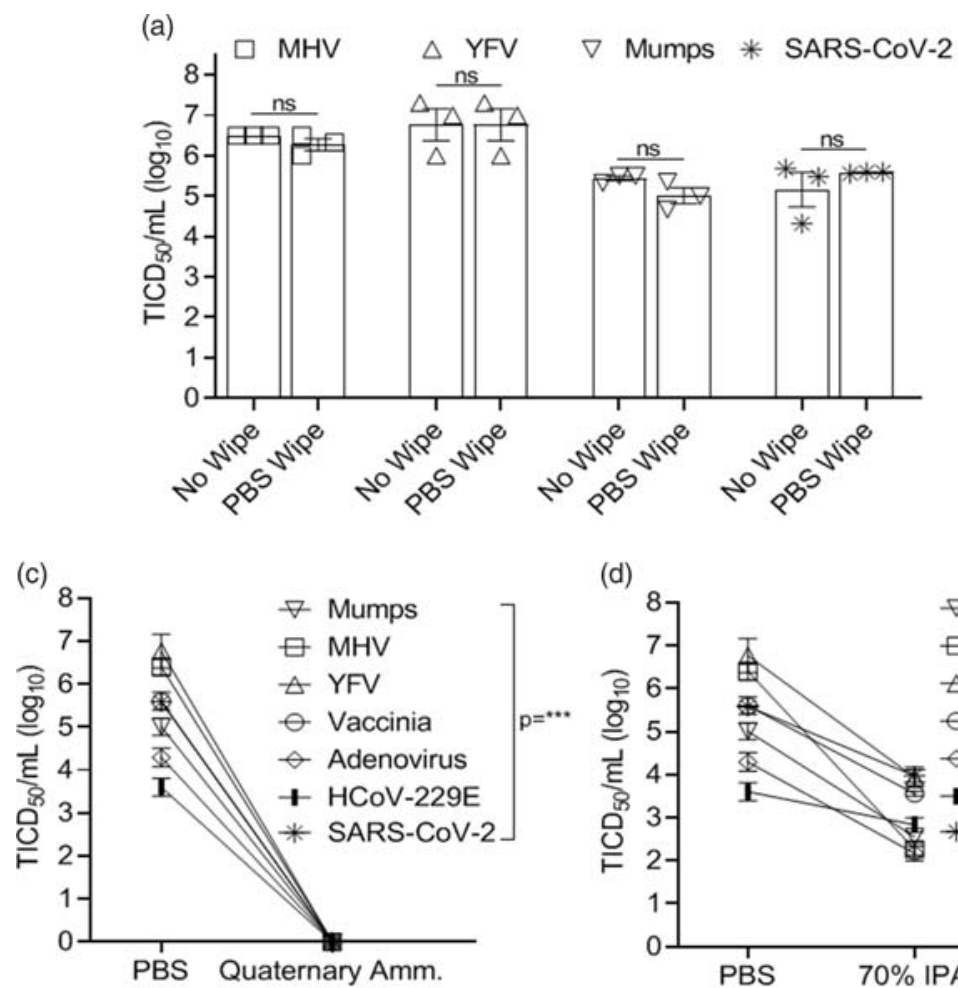
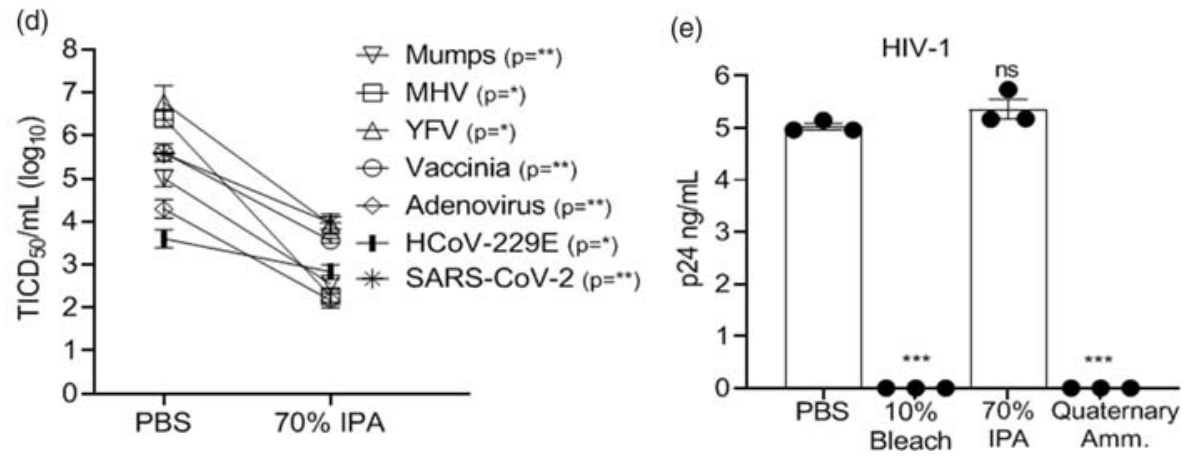

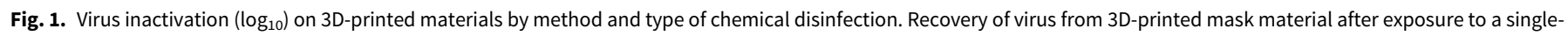
wipe application of (A) phosphate-buffered saline (PBS), (B) $10 \%$ bleach, (C) ammonium quaternary compounds, and (D) $70 \%$ IPA. (E) Recovery of HIV-1. Virus titer was completed

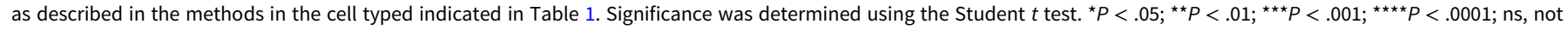

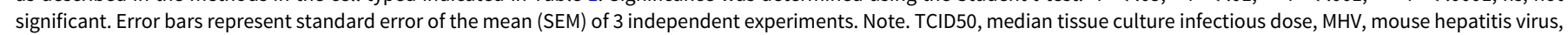
YFV, yellow fever virus, IPA, isopropyl alcohol. HIV-1, human immunodeficiency virus type 1.

controls ( $>99 \%$ of input virus recovered) (Fig. 1A). All viruses tested were exquisitely sensitive to bleach and quaternary ammonium compounds (Fig. 1B-C, 1E), and no infectivity remained following a single wipe of these disinfectants across the 3D mask material. In contrast, $70 \%$ IPA did not eliminate viral infectivity although there was $>95 \%(\geq 1.3 \log )$ inactivation of viruses applied with the exception of HIV-1, for which IPA was ineffective (Fig. 1D and $1 \mathrm{E})$. The $\log _{10}$ reduction in infectivity is shown in Table 2.

Vaporized $\mathrm{H}_{2} \mathrm{O}_{2}$ treatment of virus-coated disks utilized ionized $\mathrm{H}_{2} \mathrm{O}_{2}$ ( $\sim 3 \%$ after application) for 15 minutes of vapor contact 
Table 2. Virus Infectivity Reduction $\left(\log _{10}\right)$ by Treatment ${ }^{\mathrm{a}}$

\begin{tabular}{lccc} 
& \multicolumn{3}{c}{ Treatment } \\
\cline { 2 - 4 } Virus & $10 \%$ Bleach & $70 \%$ IPA & Ammonium Quaternary \\
\hline MHV & $>6.0$ & 2.7 & $>6.0$ \\
\hline YFV & $>6.5$ & 1.7 & $>6.5$ \\
\hline Mumps & $>5.0$ & 1.9 & $>5.0$ \\
\hline Vaccinia & $>5.5$ & 1.6 & $>5.5$ \\
\hline Adenovirus & $>4.0$ & 2.0 & $>4.0$ \\
\hline 229E & $>3.5$ & 1.3 & $>3.5$ \\
\hline SARS-CoV-2 & $>5.5$ & 1.4 & $>5.5$ \\
\hline
\end{tabular}

Note. IPA, isopropyl alcohol; MHV, murine hepatitis virus; YFV, yellow fever virus.

avalues represent the $\log _{10}$ reduction in infectivity following a single wipe application of the indicated treatment. Log reduction between viruses varied due to differences in virus inocula.
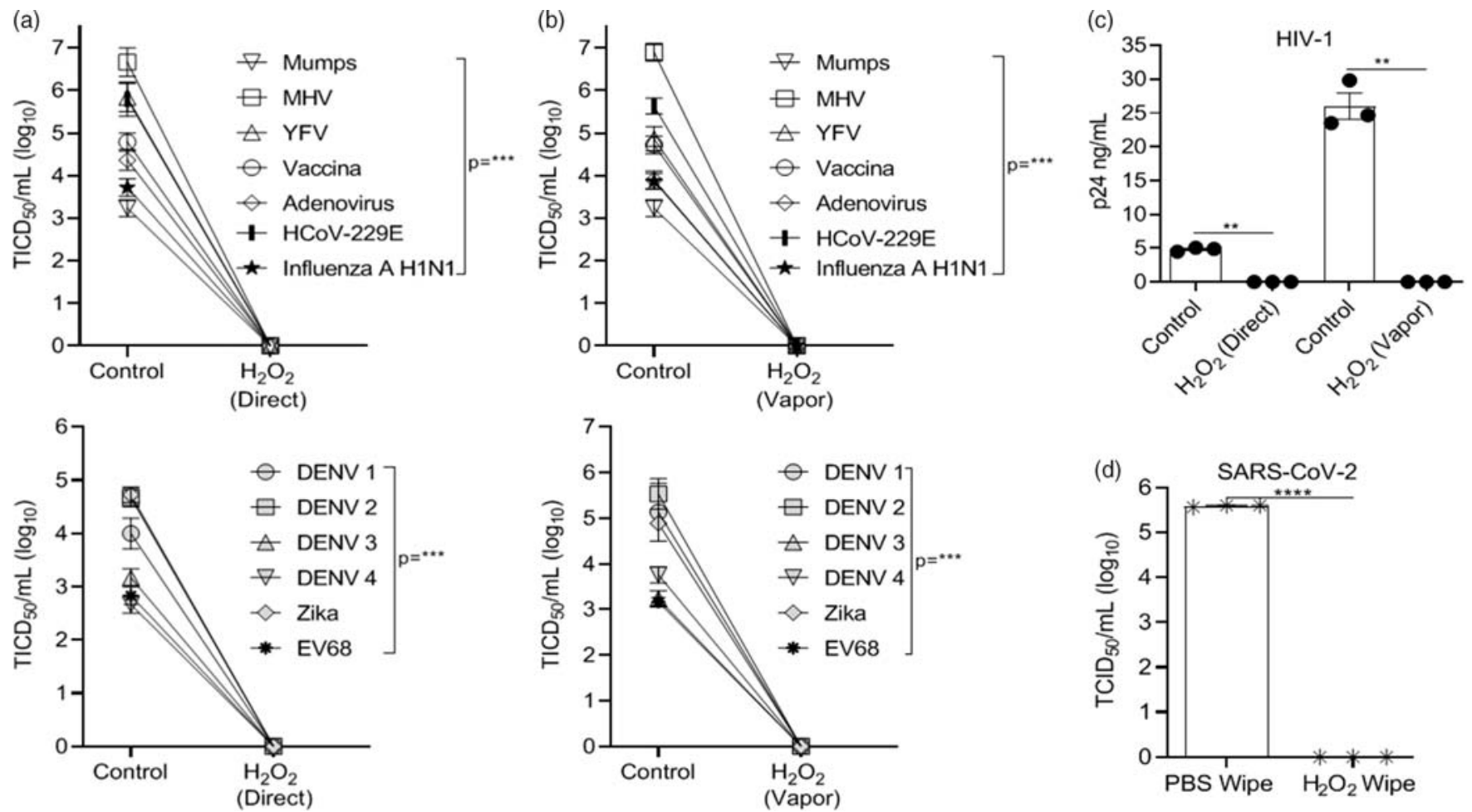

Fig. 2. Hydrogen peroxide $\left(\mathrm{H}_{2} \mathrm{O}_{2}\right)$ inactivation on 3D-print material by application method versus controls. Virus recovery from $3 \mathrm{D}$ printed mask material after exposure to ionized $\mathrm{H}_{2} \mathrm{O}_{2}(3 \%)$ in (A) direct contact or (B) vaporized application format. (C) Recovery of HIV-1. Virus applied to 3D material without exposure to $\mathrm{H}_{2} \mathrm{O}_{2}$ acted as control. (D) Recovery of SARS-CoV-2 virus from 3D-printed mask material after exposure to a single-wipe application of phosphate-buffered saline (PBS) or $\mathrm{H}_{2} \mathrm{O}_{2}$ ( $3 \%$ ). Virus titer was completed as described in the Methods section in the cell type indicated in Table 1 . Significance was determined using the Student $t$ test. ${ }^{\star} P<.05 ;{ }^{\star \star} P<.01 ;{ }^{\star \star \star} P<.001 ;{ }^{\star \star \star \star} P<.0001$; ns, not significant. Error bars represent standard error of the mean (SEM) of triplicate experiments. Note. DENV, dengue virus.

time and 15-minute air exchange using the SteraMist Binary Ionization Technology (BIT) at the University of Iowa Hospitals and Clinics Central Sterilizing Services (UIHC) in a $1.90 \mathrm{M} \mathrm{L} \times$ $1.90 \mathrm{M} \mathrm{H} \times 0.99 \mathrm{M} \mathrm{W}$ chamber. Alternatively, virus-coated disks were treated with ionized $\mathrm{H}_{2} \mathrm{O}_{2}(\sim 3 \%$ after application) in a direct contact format at a $61-\mathrm{cm}(24$-inch) distance with a minimum contact time of 4 seconds. Ionized $\mathrm{H}_{2} \mathrm{O}_{2}$ delivery was generated by passing a low-concentration source liquid $\left(7.8 \% \mathrm{H}_{2} \mathrm{O}_{2}\right)$ through a $17,000 \mathrm{~V}$ cold plasma arc. ${ }^{37}$ Both vaporized and direct contact $\mathrm{H}_{2} \mathrm{O}_{2}$ completely inactivated all viruses (Fig. 2A-C). Notably, we were not able to test inactivation by ionized $\mathrm{H}_{2} \mathrm{O}_{2}$ with
SARS-CoV-2 in the BSL3 facility. To assess the effect of $\mathrm{H}_{2} \mathrm{O}_{2}$ on SARS CoV-2, we applied $3 \% \mathrm{H}_{2} \mathrm{O}_{2}$ to the disks with a single wipe as was done with bleach, IPA, and quaternary ammonium compounds. SARS-CoV-2 was completely inactivated by $\mathrm{H}_{2} \mathrm{O}_{2}$ (Fig. 2D) using this approach.

\section{Thermal inactivation}

The effect of thermal inactivation on select viruses was examined by incubating the disks at room temperature and measuring virus recovery over time for the murine coronavirus serving as a SARS 

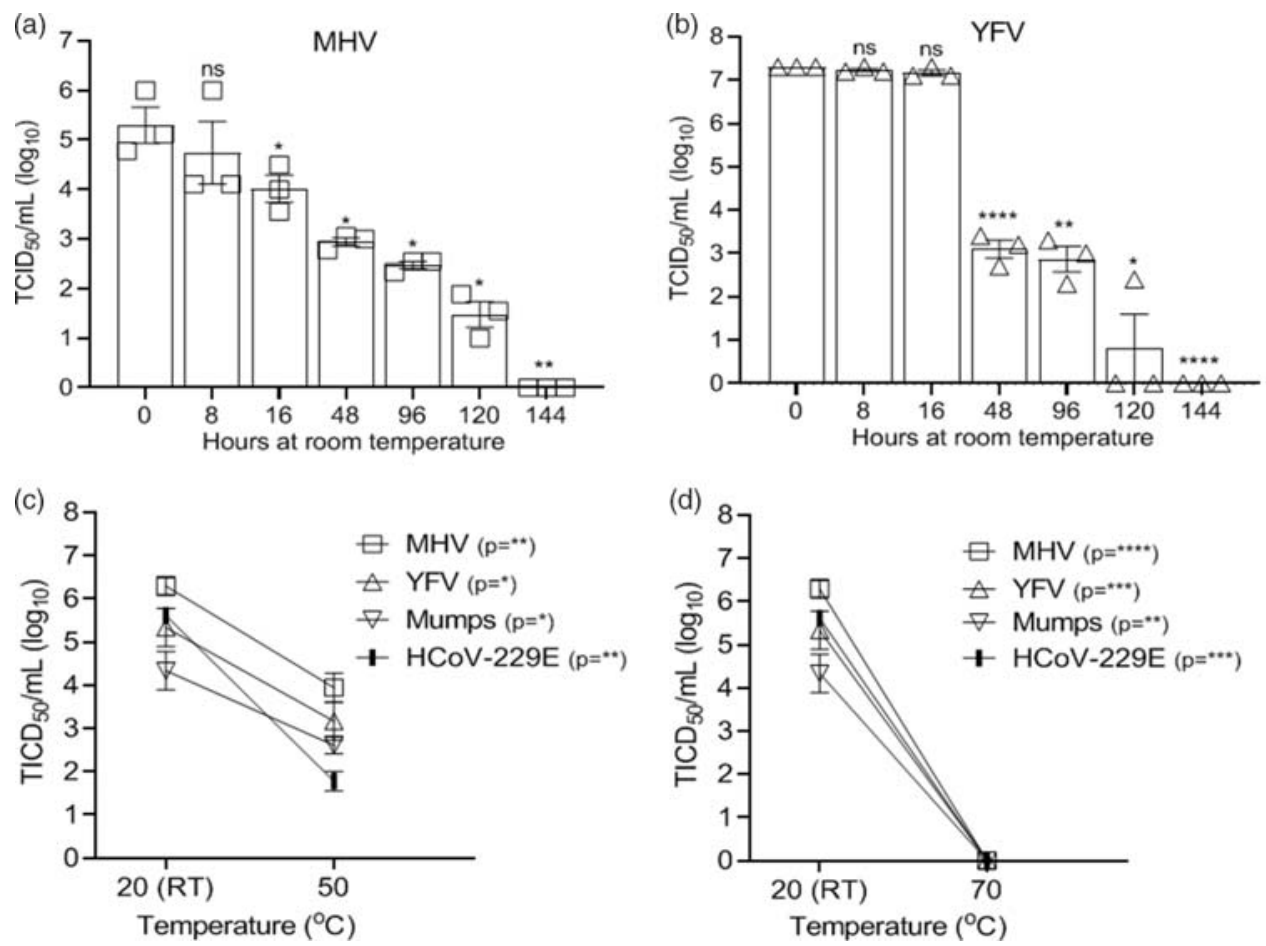

Fig. 3. Effectiveness of virus thermal inactivation. Recovery of virus over time from 3D-printed mask material incubated at room temperature $\left(\mathrm{RT}, 20^{\circ} \mathrm{C}\right.$ ) for (A) MHV and (B) YFV. Recovery of virus from $3 \mathrm{D}$ material after thermal inactivation for 30 minutes at (C) $50^{\circ} \mathrm{C}$ or (D) $70^{\circ} \mathrm{C}$. Virus incubated at $20^{\circ} \mathrm{C}$ (RT) acted as the control. Virus titer was completed as described in the Methods section in the cell type indicated in Table 1. Significance was determined using the Student $t$ test. ${ }^{\star} P<.05 ;{ }^{\star \star} P<.01 ;{ }^{\star \star \star} P<.001$; ${ }^{\star \star \star \star} P<.0001$; ns, not significant. Error bars represent standard error of the mean (SEM) of triplicate experiments.
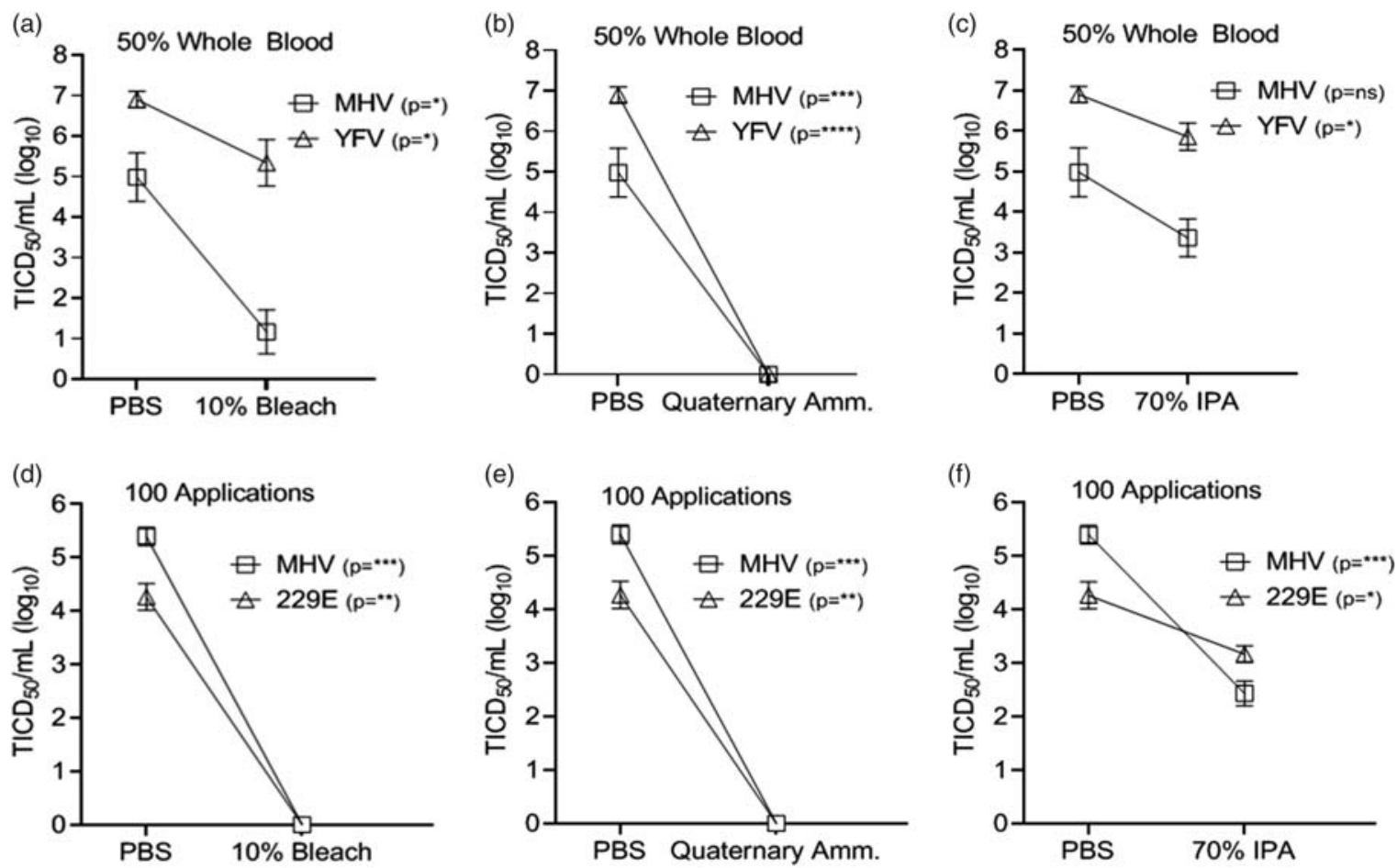

Fig. 4. Effectiveness of chemical inactivation of viruses $\left(\log _{10}\right)$ in the presence of blood and after repetitive disinfection of material. Virus recovery from $3 D$ printed mask material after virus addition to whole blood (50\% final concentration) and exposure to a single-wipe application of (A) 10\% bleach, (B) ammonium quaternary, and (C) $70 \%$ IPA. Wipe application of PBS acted as control. Virus recovery from 3D material after the material was exposed to disinfectant 100 times prior to application of virus and a single-wipe application of (D) $10 \%$ bleach, (E) quaternary ammonium, and (F) $70 \%$ IPA. Virus titer was completed as described in the Methods section in the cell type indicated in Table 1. Significance was determined using the Student $t$ test. ${ }^{\star} P<.05 ;{ }^{\star \star} P<.01 ;{ }^{\star \star \star} P<.001 ;{ }^{\star \star \star \star} P<.0001$; ns, not significant. Error bars represent standard error of the mean (SEM) of triplicate experiments.

CoV-2 surrogate (MHV) and other virus controls (YFV). As seen in Figure $3 \mathrm{~A}$ and B, MHV and YFV both required 6 days before infectivity was completely inactivated in these high-titer virus preparations. We tested select viruses (HCoV-229E, MHV, YFV, and mumps) for inactivation at $50^{\circ} \mathrm{C}$ and $70^{\circ} \mathrm{C}$ incubation for 30 minutes. Complete inactivation occurred for all viruses incubated at $70^{\circ} \mathrm{C}$. $\mathrm{HCoV}-229 \mathrm{E}, \mathrm{MHV}, \mathrm{YFV}$, and mumps viruses incubated at $50^{\circ} \mathrm{C}$ were not completely inactivated, although infectivity 

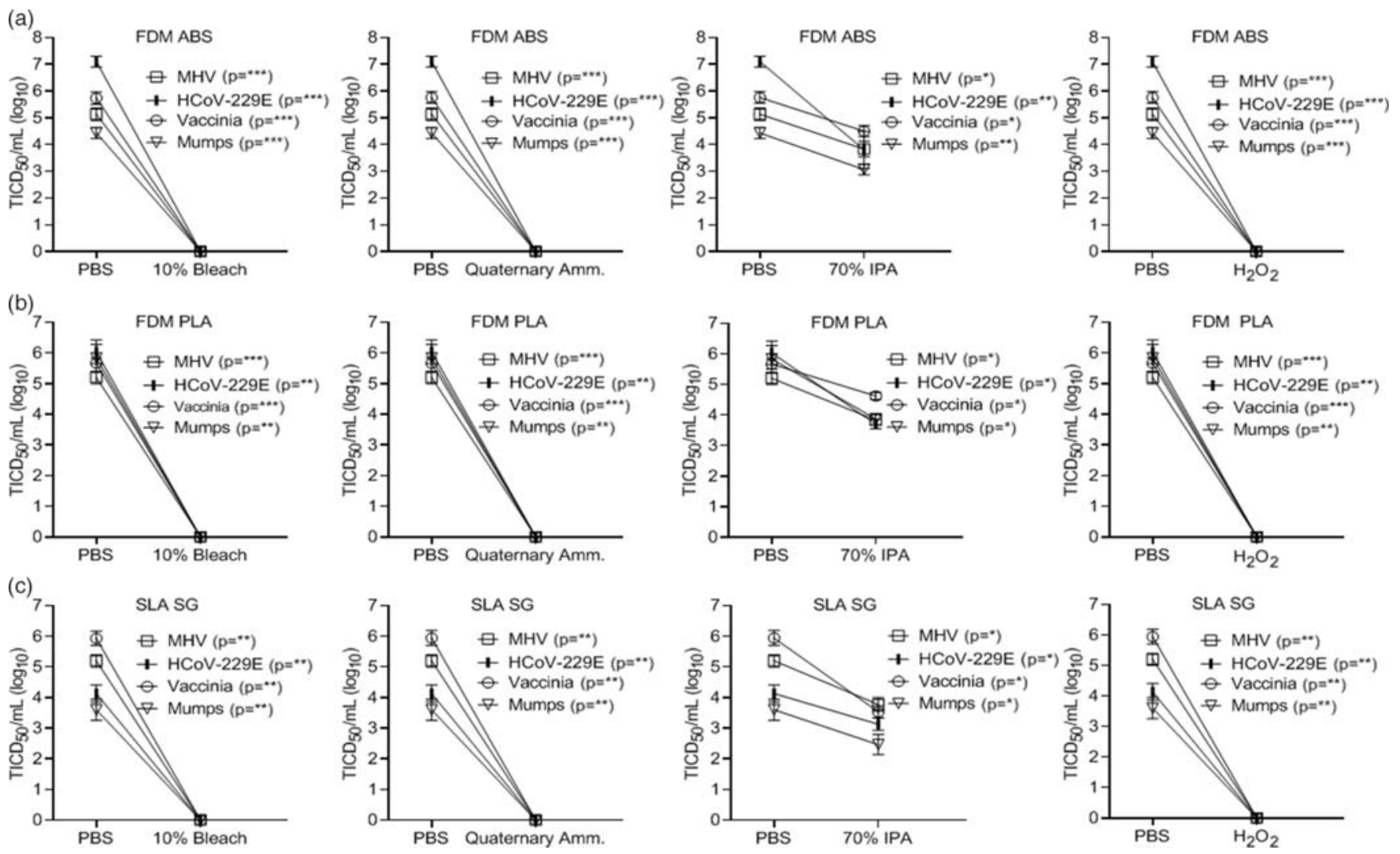

Fig. 5. Chemical inactivation of viruses ( $\left.\log _{10}\right)$ on alternative 3D-printed mask materials by type of disinfectant versus controls. Virus recovery from alternative $3 D$-printed mask material (A) FDM acrylonitrile butadiene styrene (FDM ABS), (B) FDM polylactic acid (PLA), and (C) stereolithography acrylic-surgical guide (SLA SG) after exposure to a single-wipe application of $10 \%$ bleach, ammonium quaternary, $70 \%$ IPA, and $3 \% \mathrm{H}_{2} \mathrm{O}_{2}$. Wipe application of PBS acted as the control. Virus titer was completed as described in the Methods section in the cell type indicated in Table 1. Significance was determined using the Student $t$ test. ${ }^{\star} P<.05 ;{ }^{\star \star} P<.01$; ${ }^{\star \star \star} P<.001$; ${ }^{\star \star \star \star} P<.0001$; ns, not significant. Error bars represent standard error of the mean (SEM) of triplicate experiments.

was reduced by $>97 \%(1.6 \log )$ (Fig. 3C-D). We did not have the equipment to allow testing of SARS-CoV-2 in the BSL3 at these temperatures.

\section{Effects of blood and repetitive disinfection on chemical inactivation}

Previous studies found that the presence of human blood may interfere with the viricidal activity of disinfectants. ${ }^{38}$ The effects of blood on chemical inactivation were studied by adding virus to whole blood (50\% final concentration) and testing inactivation as described above. Although disinfectant sensitivity varied between viruses in the presence of blood, viruses remained highly sensitive to bleach and quaternary ammonium (Fig. 4A-B) with infectivity reduced by $>93 \%$ (>1.2 log). IPA (70\%) did not completely inactivate the virus preparations but did reduce infectivity by at least $92 \%(1.1 \log )$ (Fig. 4C). Notably, for the MHV-blood mixture, one operator had complete inactivation, while a different operator detected a $99.9 \%\left(3 \log _{10}\right)$ reduction in inactivation with bleach application, highlighting the importance of maximizing inactivation.

An important concern for the reuse of PPE is the PA12 material's stability and resistance to disinfectants. To address the effect of repeat exposure to disinfectants on efficacy of viral inactivation, the PA12 material was exposed to 100 applications of disinfectant before virus was applied and virus inactivation assessed using a single-wipe application as described above. Following repetitive inactivation, there was no grossly apparent loss of integrity, and virus inactivation was reproducible (Fig. $4 \mathrm{D}-\mathrm{F}$ ).

\section{Alternative 3D printing materials}

In addition to the PA12 material, we tested the inactivation of select viruses on 3 materials commonly used in 3D printing applications. These included a fused deposition modeling (FDM acrylonitrile butadiene styrene (ABS) material (ABS M-30 from Stratasys, Rehovot, Israel), an FDM polylactic acid (PLA) material (PLA from Stratasys, Rehovot, Israel), and a stereolithography acrylic (SLA) material (Surgical Guide from Formlabs, Somerville, MA). These additional materials were selected because the FDM and SLA 3D-printing technology platforms are very frequently utilized, and ABS and PLA are the 2 most common materials for FDM. Further, the surgical guide (SG) material is a very popular SLA material for additional medical applications. Although these 3 materials and PA12 represent the most commonly used materials, other $3 \mathrm{D}$ printing materials have been utilized in the healthcare setting. Application of select viruses to these materials found that SLA was more impermeable, requiring longer time intervals for virus drying ( $>4$ hours), while PLA was permeable to the applied virus preparations. In contrast, ABS was similar to the PA12 material studied above. Virus inactivation by chemical disinfection was identical to that observed using the 
PA12 material (Fig. 5A-C). However, the permeability of PLA to the virus preparation would preclude use in PPE manufacture.

\section{Discussion}

The shortage of PPE during the COVID-19 pandemic created a critical need for the development of alternative, reusable equipment. However, decontamination guidelines for reusable equipment have not reached consensus and are often limited by incomplete testing against surrogate pathogens. To address the shortage of respiratory PPE, the VHA developed a 3D-printed surgical mask that may be disinfected and reused. ${ }^{8}$ In this study, we evaluated practical chemical and thermal decontamination methods for the ability to inactivate SARS-CoV-2, the causative agent of the COVID-19 pandemic, 2 surrogate coronaviruses (MHV and 229E), and a diverse set of clinically relevant human viral pathogens with different viral properties that may influence inactivation.

SARS-CoV-2 and all other viruses tested were completely inactivated by a single application of $10 \%$ bleach, ammonium quaternary, and $3 \% \mathrm{H}_{2} \mathrm{O}_{2}$ formulations. Also, $70^{\circ} \mathrm{C}$ dry heat completely inactivated viruses including the SARS-CoV-2 surrogate coronaviruses used (MHV and HCoV-229E); however, this decontamination method was not tested against SARS-CoV-2. Furthermore, 70\% IPA and $50^{\circ} \mathrm{C}$ dry heat did not completely inactivate the viruses included in this study, although viral titers were reduced by $>90 \%$ $(>1 \log )$ with these methods. Notably, in these studies, a single-wipe application of 70\% IPA did not decontaminate surfaces completely, and a more stringent application of 70\% IPA may be required for complete virus inactivation. To address the concern that blood may alter the efficacy of inactivation, we showed that virus present in $50 \%$ whole blood was reduced by $>93 \%$ when treated with a single application of $10 \%$ bleach and ammonium quaternary. These studies illustrate the potential for slight operator differences in inactivation, which highlights this potential importance when suboptimal virus inactivation chemicals (IPA) are utilized.

Ionized disinfecting mist behaves like a gas, and in our studies it was applied to environmental surfaces using 2 types of delivery devices (TOMI Environmental Solutions, trade name SteraMist). This technology is EPA-registered as a hospital disinfectant under the name "Binary Ionization Technology (BIT) Solution," and appears on EPA lists K, L, G and M. This approach was used because the antimicrobial effect is rapid ( 15 minutes), there is little damage to materials and surfaces, the $\mathrm{H}_{2} \mathrm{O}_{2}$ dissipates into water vapor and oxygen after application leaving no toxic residue or odor, and the proprietary delivery system is portable, making the adoption of this technology useful. ${ }^{37}$ This approach to disinfection was also completely effective (Fig. 2A-C).

In summary, several decontamination approaches ( $10 \%$ bleach, ammonium quaternary, $3 \% \mathrm{H}_{2} \mathrm{O}_{2}$, and $70^{\circ} \mathrm{C}$ dry heat) were effective on 3D-printed surgical mask materials. Some approaches were effective for inactivation of the SARS-CoV-2 virus, while others were also effective against its surrogates and other clinically relevant viral pathogens. These results are consistent with previous viral inactivation studies, although those studies included variations in decontamination procedures and did not incorporate virus application onto a 3D-printed material. . $^{27,39,40}$ The decontamination of 3D-printed surgical masks may be useful during crisis situations in which the supply of surgical masks is limited. Our results may be used to further study decontamination strategies for 3D-printed materials used in clinical settings.
Acknowledgments. We thank Alisha Loy (University of Iowa Hospitals and Clinics Central Sterilizing Services) and Michael J. Hartley (University of Iowa Hospitals and Clinics Hospital Administration) for assistance with the $\mathrm{H}_{2} \mathrm{O}_{2}$ inactivation experiments. We also thank Dr James McLinden and Ms Qing Chang, and Dr Catherine Loc-Carillo (Salt Lake City VA and the University of Utah) for helpful discussions and critical review of the manuscript.

Financial support. This work was supported by service-directed grants from the Veterans' Affairs (Biomedical Laboratory Research and Development Service grants to JX and JTS), a VA Merit Review Grant (no. BX 000207JTS), and the National Institute of Allergy and Infectious Diseases (grant nos. NIH 5T32AI343 JTS, NIH PO1 AI060699, SP). The funders had no role in study design, data collection and interpretation, or the decision to submit the work for publication. We thank the NIH AIDS Reagent Program for reagents.

Conflicts of interest. All authors report no conflicts of interest relevant to this article.

\section{References}

1. Jaimes JA, Andre NM, Chappie JS, Millet JK, Whittaker GR. Phylogenetic analysis and structural modeling of SARS-CoV-2 spike protein reveals an evolutionary distinct and proteolytically sensitive activation loop. $J \mathrm{Mol}$ Biol 2020;432:3309-3325.

2. WHO coronavirus disease (COVID-19) dashboard. World Health Organization website. https://covid19.who.int/. Accessed August 2020.

3. Hoffmann M, Kleine-Weber H, Schroeder S, et al. SARS-CoV-2 Cell entry depends on ACE2 and TMPRSS2 and is blocked by a clinically proven protease inhibitor. Cell 2020;181:271-280.

4. Channappanavar R, Perlman S. Pathogenic human coronavirus infections: causes and consequences of cytokine storm and immunopathology. Semin Immunopathol 2017;39:529-539.

5. Ferretti L, Wymant C, Kendall M, et al. Quantifying SARS-CoV-2 transmission suggests epidemic control with digital contact tracing. Science 2020;368.

6. Lu R, Zhao X, Li J, et al. Genomic characterisation and epidemiology of 2019 novel coronavirus: implications for virus origins and receptor binding. Lancet 2020;395:565-574.

7. Coronavirus disease 2019 (COVID-19): prevent getting sick. Centers for Disease Control and Prevention website. https://www.cdc.gov/coronavirus/ 2019-ncov/prevent-getting-sick/index.html. Accessed May 12, 2020.

8. Stopgap surgical face mask (SFM) revision B. 2020. National Institutes of Health website. https://3dprint.nih.gov/discover/3dpx-014168. Published April 30, 2020. Accessed August 11, 2020.

9. Norman J, Madurawe RD, Moore CM, Khan MA, Khairuzzaman A. A new chapter in pharmaceutical manufacturing: 3D-printed drug products. Adv Drug Deliv Rev 2017;108:39-50.

10. Kjar A, Huang Y. Application of micro-scale 3D printing in pharmaceutics. Pharmaceutics 2019;11.

11. Klein GT, Lu Y, Wang MY. 3D printing and neurosurgery—ready for prime time? World Neurosurg 2013;80:233-235.

12. Chepelev L, Wake N, Ryan J, et al. Radiological Society of North America (RSNA) 3D printing Special Interest Group (SIG): guidelines for medical 3D printing and appropriateness for clinical scenarios. 3D Print Med 2018;4:11. doi: 10.1186/s41205-018-0030-y.

13. Di Prima M, Coburn J, Hwang D, Kelly J, Khairuzzaman A, Ricles L. Additively manufactured medical products-the FDA perspective. $3 D$ Print Med 2016;2. doi: 10.1186/s41205-016-0005-9.

14. Tack P, Victor J, Gemmel P, Annemans L. 3D-printing techniques in a medical setting: a systematic literature review. Biomed Eng Online 2016;15:115. doi: 10.1186/s12938-016-0236-4.

15. Barrios-Muriel J, Romero-Sanchez F, Alonso-Sanchez FJ, Rodriguez Salgado D. Advances in orthotic and prosthetic manufacturing: a technology review. Materials (Basel) 2020;13:295. doi: 10.3390/ma13020295.

16. Murphy SV, Atala A. 3D bioprinting of tissues and organs. Nat Biotechnol 2014;32:773-785. 
17. Gross BC, Erkal JL, Lockwood SY, Chen C, Spence DM. Evaluation of $3 \mathrm{D}$ printing and its potential impact on biotechnology and the chemical sciences. Anal Chem 2014;86:3240-3253.

18. Liu DCY, Koo TH, Wong JKK, et al. Adapting re-usable elastomeric respirators to utilise anaesthesia circuit filters using a 3D-printed adaptor-a potential alternative to address N95 shortages during the COVID-19 pandemic. Anaesthesia 2020. doi: 10.1111/anae.15108.

19. Tino R, Moore R, Antoline S, et al. COVID-19 and the role of 3D printing in medicine. 3D Print Med 2020;6:11.

20. Cox JL, Koepsell SA. 3D-Printing to address COVID-19 testing supply shortages. Lab Med 2020;51(4):e45-e46.

21. Wesemann C, Pieralli S, Fretwurst T, et al. 3-D printed protective equipment during COVID-19 pandemic. Materials (Basel) 2020;13. doi: 10. 3390/ma13081997.

22. Janssens N, Huysmans M, Swennen R. Computed tomography 3D superresolution with generative adversarial neural networks: implications on unsaturated and two-phase fluid flow. Materials (Basel) 2020;13(6). doi: 10.3390/ma13061397.

23. COVID-19 supply chain response. National Institutes of Health website. https://3dprint.nih.gov/collections/covid-19-response. Published 2020. Accessed August 8, 2020.

24. Medicine I, Policy BHS, Pandemic CDRFUDI. Reusability of Facemasks During an Influenza Pandemic: Facing the Flu. Washington, DC: National Academies Press; 2006.

25. Rowan NJ, Laffey JG. Challenges and solutions for addressing critical shortage of supply chain for personal and protective equipment (PPE) arising from Coronavirus disease (COVID19) pandemic - case study from the Republic of Ireland. Sci Total Environ 2020;725:138532.

26. Recommendations for sponsors requesting EUAs for decontamination and bioburden reduction systems for face masks and respirators during the coronavirus disease 2019 (COVID-19) public health emergency. US Food and Drug Administration website. https://www.fda.gov/regulatoryinformation/search-fda-guidance-documents/recommendations-sponsorsrequesting-euas-decontamination-and-bioburden-reduction-systems-facemasks. Published 2020. Accessed July 20, 2020.

27. Kampf G, Todt D, Pfaender S, Steinmann E. Persistence of coronaviruses on inanimate surfaces and their inactivation with biocidal agents. J Hosp Infect 2020;104:246-251.
28. Welch JL, Xiang J, Okeoma CM, Schlievert PM, Stapleton JT. Glycerol monolaurate, an analogue to a factor secreted by lactobacillus, is virucidal against enveloped viruses, including HIV-1. mBio 2020;11. doi: 10.1128/ mBio.00686-20

29. Mohr EL, Xiang J, McLinden JH, et al. GB virus type C envelope protein E2 elicits antibodies that react with a cellular antigen on HIV-1 particles and neutralize diverse HIV-1 isolates. J Immunol 2010;185:4496-4505.

30. Smee DF, Hurst BL, Evans WJ, et al. Evaluation of cell viability dyes in antiviral assays with RNA viruses that exhibit different cytopathogenic properties. J Virol Methods 2017;246:51-57.

31. Hassan AO, Case JB, Winkler ES, et al. A SARS-CoV-2 infection model in mice demonstrates protection by neutralizing antibodies. Cell 2020;182:744-753.

32. Winokur PL, McLinden JH, Stapleton JT. The hepatitis A virus polyprotein expressed by a recombinant vaccinia virus undergoes proteolytic processing and assembly into viruslike particles. J Virol 1991;65:5029-5036.

33. Maitz MF. Applications of synthetic polymers in clinical medicine. Biosurface and Biotribology 2015;1:161-176.

34. McLinden JH, Bhattarai N, Stapleton JT, et al. Yellow fever virus, but not zika virus or dengue virus, inhibits T-cell receptor-mediated T-cell function by an RNA-based mechanism. J Infect Dis 2017;216:1164-1175.

35. Qing E, Hantak M, Perlman S, Gallagher T. Distinct roles for sialoside and protein receptors in coronavirus infection. mBio 2020;11. Doi: 10.1128/ mBio.02764-19.

36. Knipe DM, Howley PM, editors. Fields Virology, 6th ed. Philadelphia: Lippincott Williams \& Wilkins; 2013.

37. Cramer A, Plana D, Yang HL, et al. Analysis of SteraMist ionized hydrogen peroxide technology in the sterilization of N95 respirators and other PPE: a quality improvement study. medRxiv 2020. doi: 10.1101/2020.04.19.200 69997.

38. Weber DJ, Barbee SL, Sobsey MD, Rutala WA. The effect of blood on the antiviral activity of sodium hypochlorite, a phenolic, and a quaternary ammonium compound. Infect Control Hosp Epidemiol 1999;20:821-827.

39. Dembinski JL, Hungnes O, Hauge AG, Kristoffersen AC, Haneberg B, Mjaaland S. Hydrogen peroxide inactivation of influenza virus preserves antigenic structure and immunogenicity. J Virol Methods 2014;207:232-237.

40. Zou S, Guo J, Gao R, et al. Inactivation of the novel avian influenza A (H7N9) virus under physical conditions or chemical agents treatment. Virol J 2013;10:289. 